\title{
Language Borrowing between Arabic and Yoruba Language
}

${ }^{1}$ Abdur-Rasheed Mahmoud-Mukadam, ${ }^{2}$ Abdulwahid Aliy Adebisi

University of Ilorin, Nigeria

e-mail : ${ }^{1}$ mukadam.am@unilorin.edu.ng, ${ }^{2}$ adebisi.aa@unilorin.edu.ng

Arabic Language is characterized by a great deal of influence that has made a profound impact on the rest of the world's languages, whether socially, culturally, religiously or economically. This language is specific to the Holy Quran, which has a higher constitution that Muslim takes from the laws of religion. Islam does not solve a place except it takes with language of its Arabic provisions. This article sheds light on some of the words borrowed by Yorba from Arabic in its various forms, of which there is no change in the image of

Abstract pronunciation and what has undergone some change and distortion. The approach envisaged in this article is inductive, thus contributing in one way or another to supporting some scientific and historical facts in this area of borrowing. The results of this article is that language of the world is estimated relative to the world's speakers by $6.6 \%$ and the largest languages that borrow some others words in the corridors of life. Yorba, the language of southern Nigeria, and one of the three most famous tribal languages (Hausa, Yorba, Ibo) and which also has many of the speakers borrows many from Arabic.

Keyword Arabic Language; Borrowing; Yoruba Language

$$
\begin{aligned}
& \text { اللغة العربية بين سائر اللغات تتميز بميز كثيرة جعلتها تؤثر في بقية اللغات }
\end{aligned}
$$

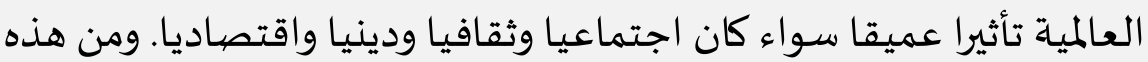

$$
\begin{aligned}
& \text { الميز أنها لغة تختص بالقرآن الكريم الذي هو دستور أعلى يأخذ منه المسلم }
\end{aligned}
$$

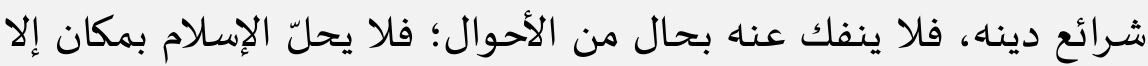

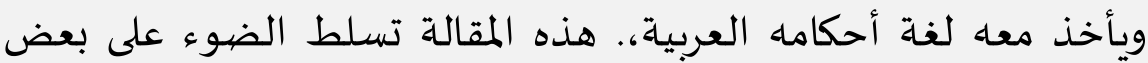

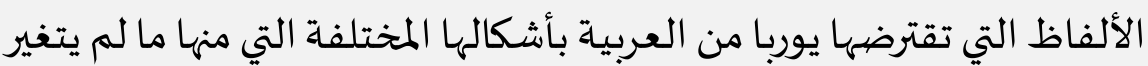

$$
\begin{aligned}
& \text { صورة النطق بها وما قد طرأ عليه بعض تغيير وتحريف. والمنهج الذي يتوخاه }
\end{aligned}
$$

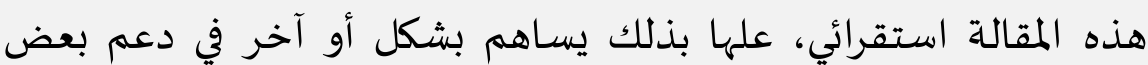

$$
\begin{aligned}
& \text { الحقائق العلمية والتاريخية في هذا مجال الاقتراض اللغويّ. وكانت نتائج }
\end{aligned}
$$

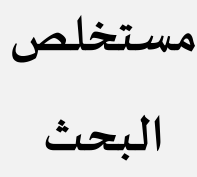

Please cite this article as Abdur-Rasheed Mahmoud-Mukadam and Abdulwahid Aliy Adebisi. (2019).

Language Borrowing between Arabic and Yoruba Language. Izdihār : Journal of Arabic Language Teaching, Linguistics, and Literature, 2(1), 53-66. DOI: https://doi.org/10.22219/jiz.v2i1.7386 
البحث هي هذا الأسـاس القويّ لا يعد اللغة العبية لغة قبيلة دون أخرى، وليست بلغة شعب دون آخر بل إنها لغة العالم تقدر نسبية الناطقين بها في العالم كله بـ 7,7\% وكانت أكبر اللغات التي تقترض منها غيرها بعض ألفاظها دولها في مسارب الحياة كلها. وتقترض منها-كثيرا- لغة يوربا التي هي لغة جنوب نيجيريا، وهي أحد ثلاث لغات قبلية مشهورة فيها (هوسا، يوربا، إيبو) وكثر عدد الناطقين بها.

لغة عربية؛ اقتراض؛ يوروبا كلمات أسـاسية

مقدمة

تعتبر اللغـة العربيـة سيّدة اللغـات العالميـة بائدتها وباقيتها، وتحقّقت لها هـذه السيادة من وجود عوامل موجبـة لذذلك؛ كان مـن بينها عامل اقتصـاديّ، وعامل سياسيّ، وعامل دينيّ، وعامل لغوي (El-Houryan, 2003, pp. 68-69) وكلُّ من هذه العوامل عملت لصيالح العربية القرشيّة الفصيحة قداسـة وشهرة وذيوعا، بالإضيافة إلى أنهّا لغـة ثريّة تتميز بين غيرهـا من اللغات العالميـة؛ وهي تقترض لسانها في ثنايا التعابير لسلاساة نطقها وجودة ألفاظها وبيان دلالتها.

ومن أكثر لغاتٍ اقتراضـا لبعض مفرداتها من العربية لغة يوربا، التي هي إحدى ثلاث لغات محلِّيّة مشهورة في نيـجيريـا؛ وهي لغـة أهل جنوبها الغربي التي يبلـغ عـدد النـاطقين بها-في الـداخل وخارجها من توغو ، وسـاحل العـاج وبنين-وغانا، وأروبـا، والأمريكيـة الشمالية أربعين مليون نسـمة (Wikipedia, 2016) وتقترض يوربا من العربية بعد أن عرفت العربيّة سبيل توغّلها

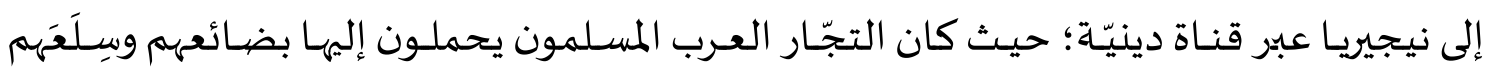
للتسـويق، فحصـل الاحتكاك الـذي اشـترط أسـاسيا في حسدوث الاقتيراض بين اللغـة المانحـة واللغـة المتلقّية (El-Afriqiyah, 2008, p. 443) وذلك من خلال الاحتكاك المفترض بين البائع والمشتري طفقـت اللغــة العربيـة تتسـرّب في لسـان أهـل نيجيريـا، وأصـبـحت كلمـات عربيـة جديـدة تـدخل في اللغـات المحلية وخاصـة في لغـة الهوسـا التي كانت ولا تزال اللغـة التجاريـة السـائدة في غربي إفريقيا؛ دخلت فيها مثلا أسماء بعض البضائع المستوردة من البلاد العربية والتي لم تكن معروفة عند أهلها قبـل ذلك مثل: الحريـر والزعفـران والسـرج وغيرهـا، ودخلـت العقـود مـن الأعــاد مـن عشـرين إلى تسـعين، وبعـض الكلمـات التي لا يسـتغني عنهـا التجّهـار كالغشّ والأمانــة وأمثالهمـا، فهـده الكلمـات 
Galandathi, 1982, p. ) دخلت في بعض اللغات المحليّّة النيجيريّة مثل: هوسـا، وفلاته، ويوربا 71) ، كما وجـد التـديّن بالإسـام سبيل التوصّّل إلى أعماق صيدور أهلها عقيدة وسـلوكا، فعلى هـذه الدّربة اللّفويّة المتواصلة تداخلت اللغتان، فطفت اللغة المانحة على اللغة المتلقيّة في بعض ألفاظ مفرد اتها وبعض اصطاحاتها اللّغويّة؛ فأدت هذه الظاهرة إلى الاتّحاد التامّ بين اللّنتين في كثير من El-Iloriy, 2012, p. ) مفردات الكلمات العربيّة التي إذا تُرجمت إلى يوربا تبقى كما هي في العربيّة 126) وليسـت يوربـا وحسدها مـن اللغـات المحليـة في نيجيريـا ت تقتيرض بعض ألفـاظ مفرداتهـا مـن العربية بل كانت غيرها مثل هوسا وفلاتها مقترضـة منها، وشـاعت الألفاظ العربية في لغذة هوسـا حتى تظن باحثة (Arokoyo, 2012, pp. 131-132) أنها في الأصالة ألفاظ هوسـاوية اقترضتها منها يوربا مثل كلمـة البصـل، والعافيـة، والبركـة؛ وذلك لعـدم معرفتها بأصـالة عربيـة هـذه الكلمـات، وإنمـا أخذتها لغة هوسا من العربية مثل أخذ غيرها من اللغات.

\section{مفهوم الاقتراض اللغوي}

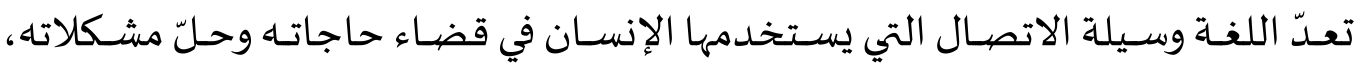
والاتصـال بالأفراد والجماعات ويستخدمها فيما يتصـل بتنظيم نـواحي نشـاطها الإداريّة والسياسيّة والاقتصياديّة والاجتماعيّة (Madkour, 1991, p. 35) ولا تحلو الحياة لأيّة لغة من اللغات إذا لم تخـرج مـن منطقتها فيكون شـيوعها ومعرفتها في تنقّل أهلها من مكان إلى آخر حسب الاحتياجـات

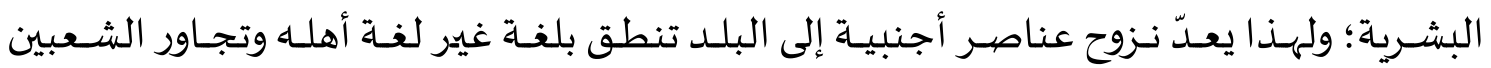
مختلفي اللغـة فيتبـادلا المنـافع ويتـاح لأفرادهما فرص الاحتكاك الماديّ والثقافيّ أهم العوامل التي ينشأ عنها الاحتكالك أو الصراع (Ed-Deen, 2010, p. 181) فتحصل ظاهرة الأخذ والعطاء، أخذ الألفاظ وعطائها، أو ما تسهى ظاهرة التبادل اللغويّ التي هي أبرز ظواهر التأثير والتأثّر بين اللغات فمن خلال التعايش بين اللغـات يأخـذ بعضها من بعض من خلال (El-Kazourey, 1988, p. 9) الظروف التي تطرأ وتفترض الاتّصـال بين الشعوب المختلفة فينشأ منـه الاتّصـال والاحتكاك اللغويّ ودخـول كلمـات جديـدة إلى لغــة مـن غيرهـا، وقـد اصـطلح علمـاء اللغـة على هـذه الظـاهرة الاقتراض اللغويّ (Ed-Deen, 2010, p. 183.

والاقتراض في المدلول اللغويّ هو كلمة مأخوذة من مادّهها الثلاثيّة الأصليّة (ق ر ض)، وهو مصيدر اقترض يقترض اقتراضـا. واقترضتها منـه أي أخـذت منـه القروض، وأقرضيه أي أعطاه قرضيا، 


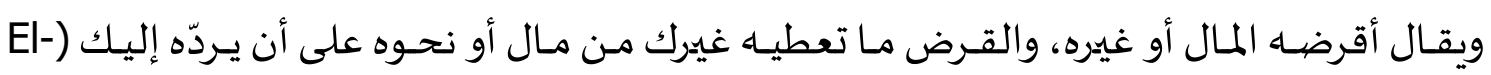
.(Fayrouzabadey, p. 733

وفي اصطلاح علماء اللغة : فهو إدخال أو استعارة ألفاظ أو غيرها من لغة إلى لغة أخرى. وقد استعمل أهل اللغات ألفاظا معيّنة لهذه الظاهرة منها لفظ الاقتراض Borrowing والنقل والاستعارة Emprunt والإدخال Innovation كما أطلقوا على الألفاظ المقترضة التي أضافوها إلى فها

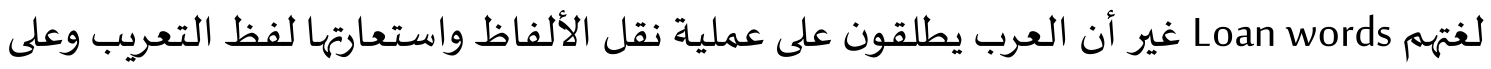

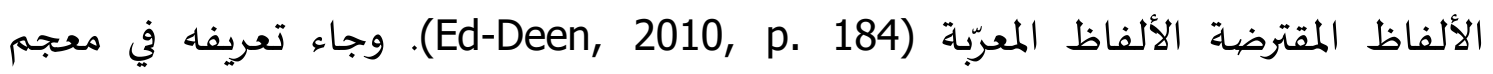
المصطلحات العلميّة أنها إدخال عناصر من لغة ما إلى لغة أخرى أو من لهجة إلى لهجة أخرى سواء الهراء

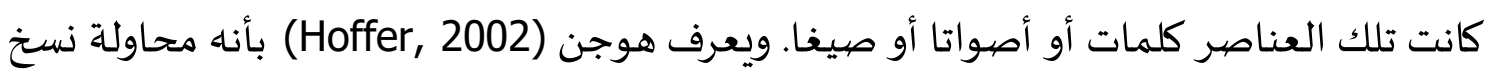

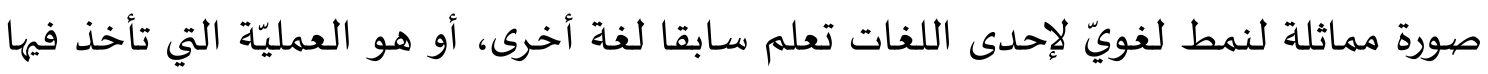
إحدى اللغات بعض العناصر اللغويّة للغة أخرى؛ غير أن محمد علي الخولي قد فرّق بين التدخيل

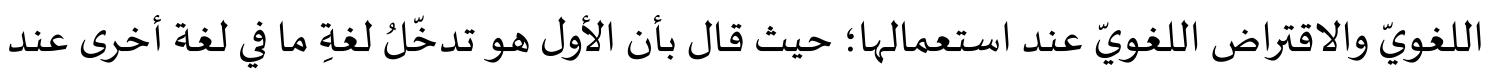

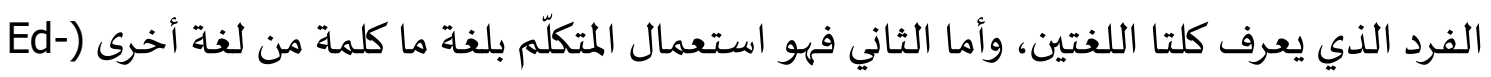

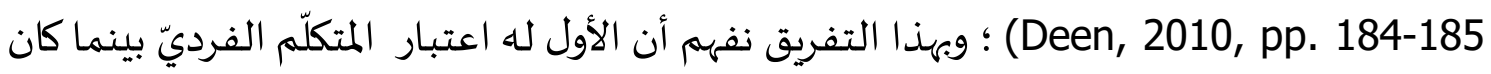

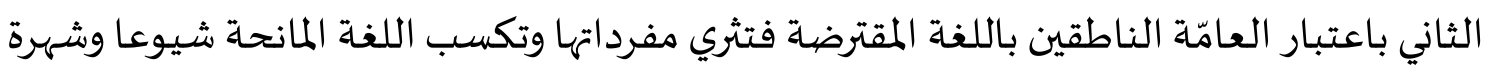
مما يجعل أن يعد الاقتراض اللغويّ أحد مظاهر ثرائيّة اللغة .

\section{ثرائية اللغة العربية ومظاهرها}

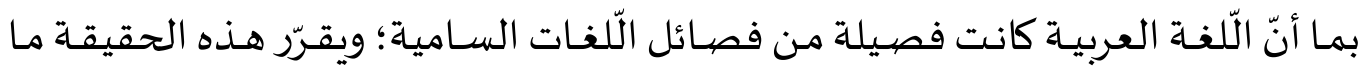

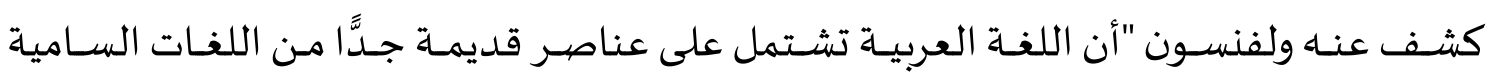

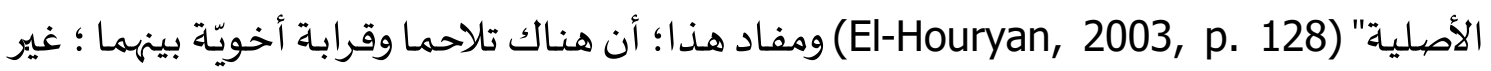

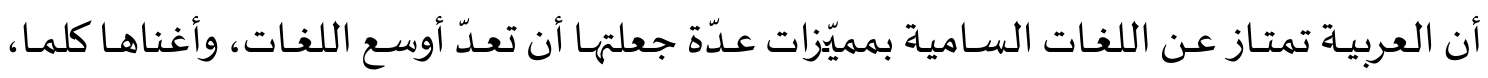

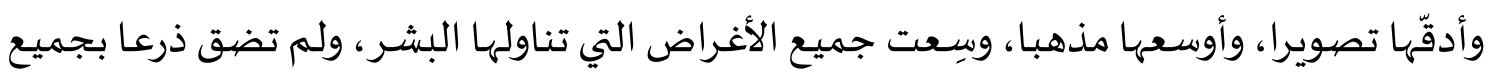

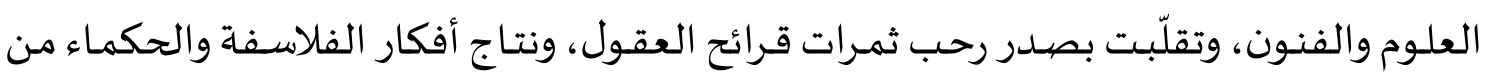

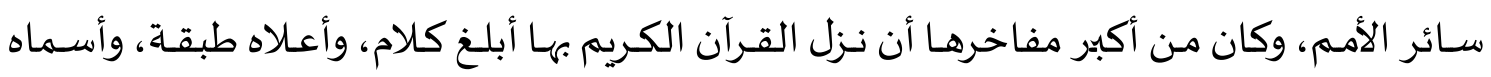

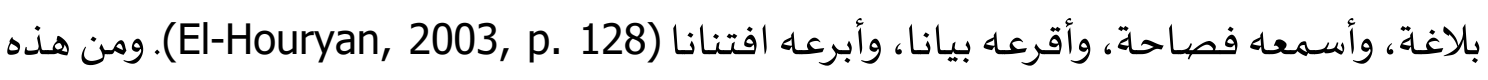

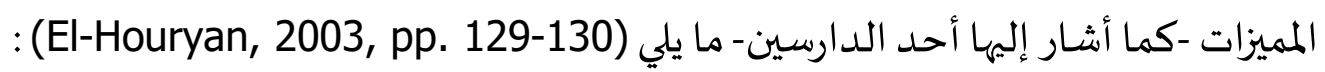


وفرة المادّة اللغويّة الموجودة في بطون المعاجم، والتي جمعت فأوعت على اختلاف مناهجها، وتوزّع مدارسها بين المعاجم العامة والخاصة.

ب) كمال الإعراب الذي بها أدّت كل الأغراض في تمام أداء، وهو وإن وجـد في اليونانية، فلعلّه ليس بالكمال الموجود في العربية، فلقد رسخت قواعده في نفوس العرب حتى صار بمرور الأيام سليقة وطبعا.

الإيجـاز الذذي ظهر واضشحا في كثيرة الحـذف، فلك أن تحـذف المضـاف والموصيـوف والخبر

$$
\text { والمبتدأ، وكل ما دلّ عليه دليل لتحاشي الإطناب المملّ. }
$$

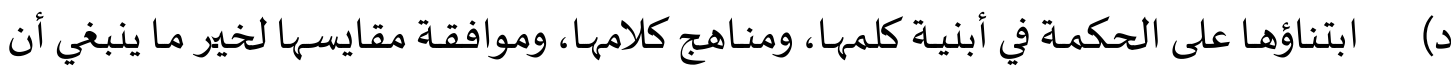
يراعى، والتزام أهلها لهذه المقاييس، لا يكادون يخرجون عنها إلا لشيء يضطرون إليها كما

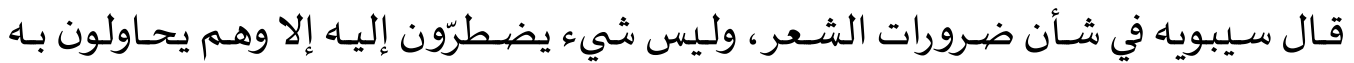
وجها (El-Houryan, 2003, p. 130).

وهـن المعيـار الـذي تنبني عليـه ثَرائيتهـا ظـاهرة التيترادف اللغـويّ وإن كانتـ هـذه الظـاهرة

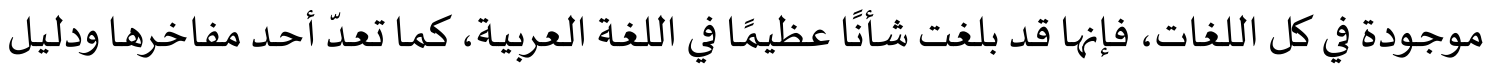

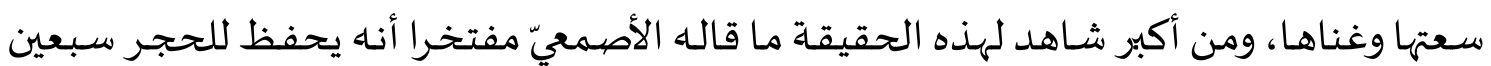

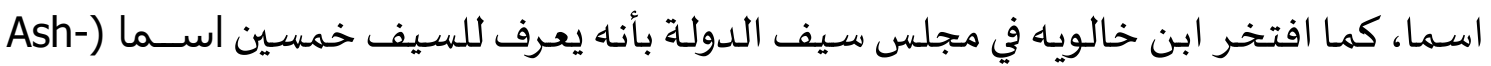

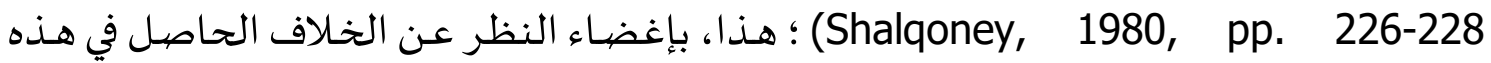
الظاهرة؛ حيث يوجد لها الاتّجاهان المتباينان من التأييد والمعارضية؛ فمن معارضيها ابن الأعرابي

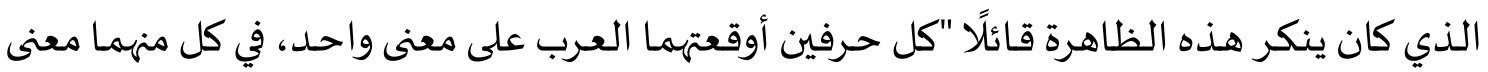

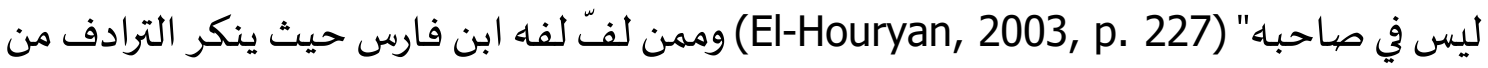

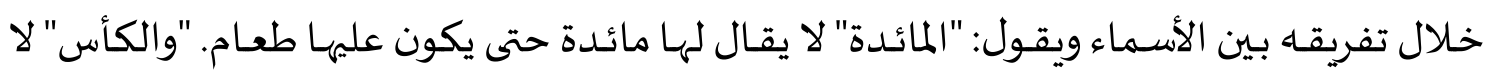

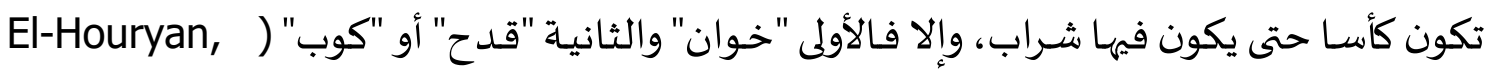
(2003, p. 227 "جلس" فالقعود يكون عن قيام، والجلوس يكون عن اضطجاع، فالجلوس ارتفاع عما هو دونها.

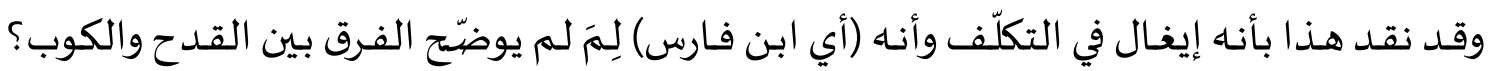

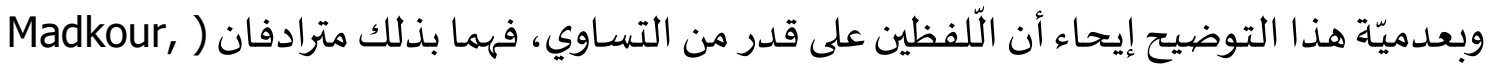


1991， p. 48

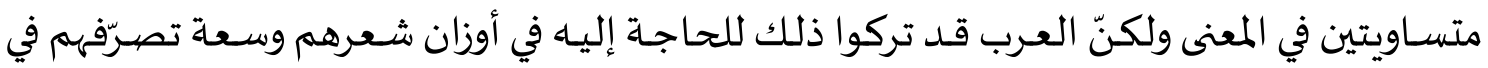

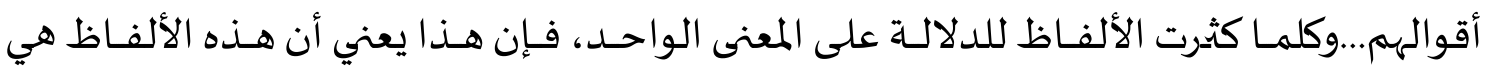
استعمالات لجماعات أو قبائل مختلفة، لكنّ هذه الألفاظ اجتمعت لإنسـان واحد من هنا وهناك الك الكان (Jinney, _, p. 310)

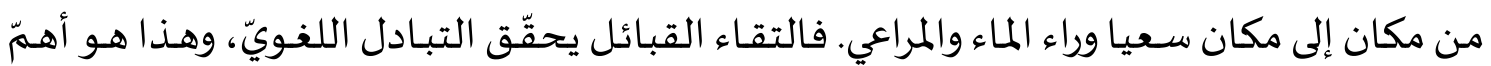
أسباب الترادف. والحقيقة أن هذه الظاهرة مازالت موجودة حتى يومنا هذا. فهناك مسمّيّات كثيرة

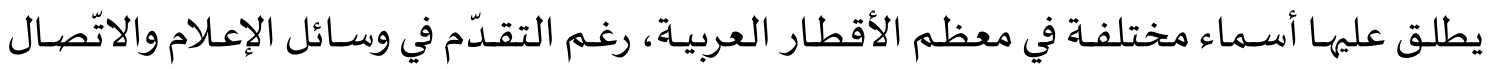

(Madkour, 1991, p. 49)

كما تجلو ثرائيّة اللغة العربية من أزياء الاشتقاق الذي كان-ولايزال- يكسب لها غزارة لغويّة

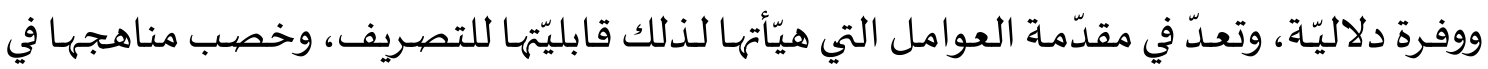
الاشتقاق، وكثرة صيغها وأبنيتها، وجريان الاختلاف فهيها على حسب اختلاف المعاني والأغراض (El-) (Houryan, 2003, p. 147 وقد اتّخذه الأسلاف مخرجا عند ما اضطرتهم ظروف الحياة المتجدِّدة

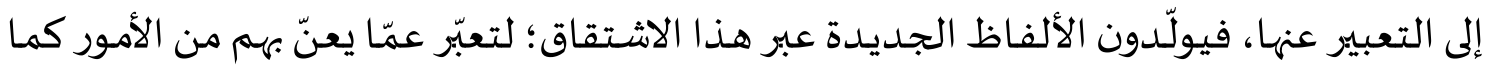

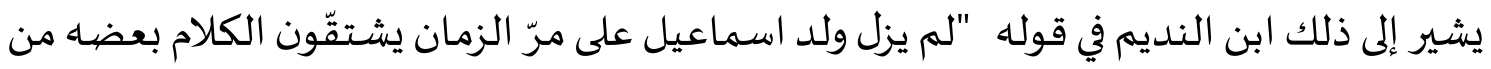

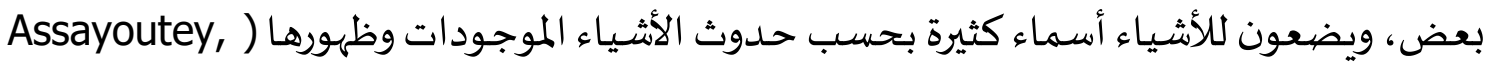
p. 351

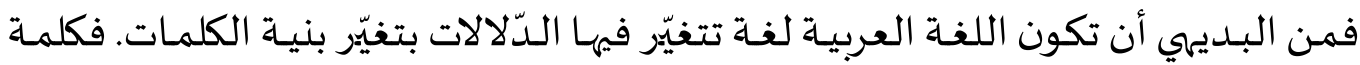

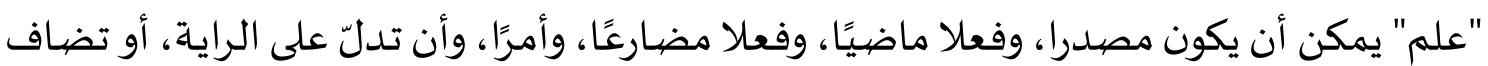

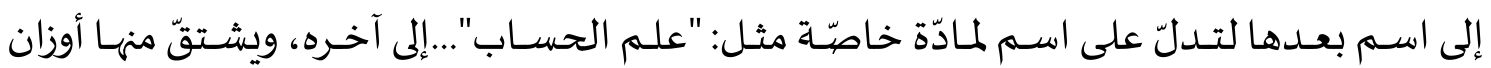

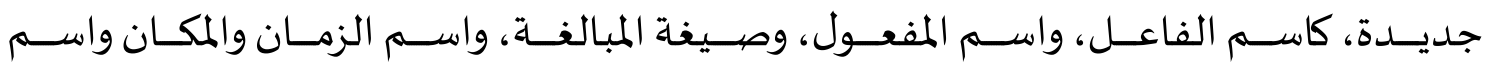
التفضيل...وهكذا...يبرز مع كل تغيير جديد في الكلمـة معنى جديد. فإن مرونة العربية وطواعية

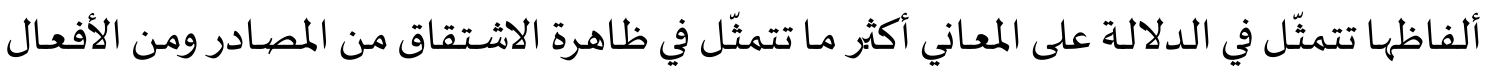

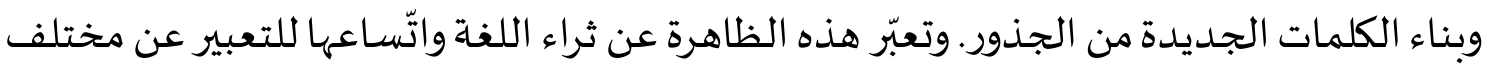
المطالب والحاجات (Madkour, 1991, pp. 49-50). 
ومن الظواهر التي تبدو في أزيائها ثرائيّة اللغة العربية ظاهرة التعريب (الاقتراض) التي هي

Assihah, Ellisan el-) عبارة عن صبغ الكلمة بصبغة عربية عند نقلها بلفظها الأجنبي إلى اللغة Arabi, Ettaj el-Aroos; Madat Araba, Dakhala محضية استعانت بها العربية، لا تتبع من صهميمها، ولكنّا تزوّدها بما يبعث حيويّها، ويوسّع آفاقها، وقد كان لهذه الوسيلة آثار واسعة المدى في زيادة الثروة اللفظيّة في العربيّة، وأعانتها على استيعاب حضارات عميقة، وعلوم ومعارف متنوّعاة، وثقافات شتى لم يعرفوها، وأفكار وأنظار لم تخالج عقولهم قبل، وقد تأصيّلت هذه الظاهرة في العربية منذ عصرها الأول الجاهليّ قبل ظهور الإسلام ويثبت هذا أن الدكتور صلاح الدين المنجد قد جمع شواهد اثنين وأربعين من شعراء الجاهلية يشتمل كل منها على كلمة أو ما فوقها من الفارسية)(El-Munjid 1978; 3ما يتمثّل عبد الله بن عباس أول من أثر عنه كلام في اشتمال القرآن على كلمات ذات أصل أجنبي ثم تابعه فريق ممن جاء بعده (El-Houryan, 2003, p. 190)؛ غير أنّ اللغويّين لم يكونوا على اتجّاه واحد تجاه قضيّة وجود التعريب في القرآن فمنهم من ينكر ومنهم من يؤيّد، ولسنا في صهدد الحديث عن ذلك.

\section{دو افع الاقتراض اللغوي}

إن ظاهرة الاقتراض اللغويّ ليست نتيجـة-بالاطراد-عن الضعف أو الفتور الحاصل في لغة

مـا؛ فيكون في موجب ذلك أن تتقوّى تلك اللغـة الضـعيفة بـالاقتراض من غيرهـا لسـدّ ثفرهـا وإثراء مفراداتها؛ كما ذهب إليـا بعض الباحثين؛ حيث قوله بأن بعض اللغـات تستعين بألفـاظ البعض الآخر وأسـاليبه في سـدّ حاجاته مـن المفردات والتعبيرات التي تعـوزه والتي تصبح فيما بعـد جـزء من تلك اللغات، ولا غرو في أن هذا الدافع هو السبب الشائع في كل اقتراض لغويّ وهو أمر ينطبق على اللغات جميعا في أغلب الحالات (Ed-Deen, 2010, p. 190) فهذا التعبير -عندنا- تعوزه الدقّة؛ لأن اللغة العربية التي تعدّ إحـدى أثرى اللغات العالميّة اقترضت بعض مفرداتها وألفاظها من غيرها من اللغـات الحيّة مثل أخـذها من الفـرس والروم والنبط والأحبـاش وغيرهم؛ أخـذت هـذه الألفـاظ

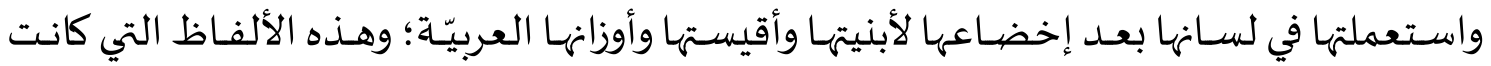
، أجنبيّة الأصيل ودخلت العربيّة تسهى المعرِّة أو الدخيلة (Esh-Shuwayrif, 1379 H, p. 103) فهل اقترضت العربيّة تلك الألفاظ من غيرهـا لسـدّ حاجاتها من المفردات والتعبيرات التي تعوزهـا؟ فإنما كان ذلك من قبل التأثير والتأثّر الّذّين يحـدثان بين اللغتين المتجـاورتين؛ مع أن هذه الظاهرة تضهمن البقاء للغـة المانحة؛ لأنها تعتبر ظاهرة صديّة في مسيرة تطوّر أيّ لغـة تريد البقاء في العالم 
فيكون سرّ هذا البقاء في اقتراض ألفاظها وبعض مفراداتها للغة أخرى ليست لها من أب وأحّ، مثل ما لعبت العربية دورا ملموسـا في بقاء تلكم اللغات التي اقترضت منها فتلوكها ألسنة الناطقين بها على حساب العربية. ومن دوافع الاقتراض ما يلي:

الإضــافة للألفــاظ دلالات جديــدة تتلــون بتلــوّن العصــور واخـتلاف المجتمعــات والثقافـات فتتحقق الغاية المنشـودة في أن اللغـة أداة للتبـادل الاجتماعي والتلاقي الثقافي بين الحضـارات، فلا نستغرب -بعيدا- أن نجـد لغة ما تقترض لفظة من لغـة أخرى وتـلـخل في نسيجهها البنيويّ والسياقي بعد أن تنصهر في القالب التركيبي والصرفي للغة الوافدة إليها (El-Afriqiyah, 2008 كما نجـد ذلك في شـأن اقتراض كثير اللغـات المحلّيـة في نيجيريـا بعض ألفاظها من العربية التي أثّرت فيها تأثيرا كبيرا مع كونها تعدّ بهذا التأثير من قبيل تأثير الطبقة الدنيا حسب تقسيم علماء اللغـة (El-Afriqiyah, 2008, p. 444) لأنماط التأثيرات التي تحسدثها بعض اللغات في بعضها الآخر؛ فهذه الأنماط الثلاثة هي : تأثيرات من الطبقة الدنيا Substratum وتأثيرات من الطبقة الوسطى Adstratum، وتأثيرات من الطبقة العليا Superstratum ؛ فأما الأولى يقصــد بها ذلك التـأثير الـذي يحـدثـه اللغــة غيير السـائدة سياسـيّا أو ثقافيّا على اللغــة السـائدة في المنطقة، وهو ليس لله دائما أثر على معجم اللغـة المقترضية مثل شـأن ألفاظ اللغـة العربيـة المقترضــة للغـات النيـجيريّة. وأمـا الثانيـة فهي الوضـع الـذي تكون فيـه لغتـان في حالـة احتكاك، ولا تتميز أيّ منهما بسيادة ثقافيّة أو سياسيّة؛؛ ففي هذه الحالة لا نستطيع أن نجزم

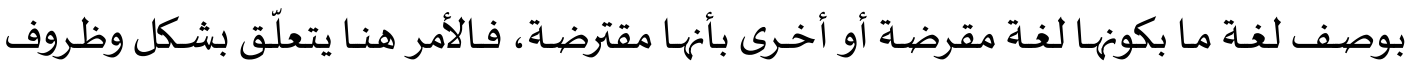
الاقتراض وطبيعـة اللغـات، فاللغـة المقرضـاة للغـات أخـرى قـد تقترضرض من هـذه اللغـات أو مـن غيرهـا تحـت ظـروف معيّنــة، وإن كان هـذا الاقتيراض يحـدث بنسـب متفاوتـاة ويخضـع لعوامـل اجتماعية وثقافية مثل الاقتراض الحاصل بين اللغات المحلّية الداخلية. وأما الثالثة يقصيد بها تأثير اللغة السائدة سياسيّا وثقافيّا على اللغة الأخرى أو اللغات في نفس المنطقة. ميل أصسحاب اللغـة المقترضـة إلى الترف التعبيريّ والتفـاخر بلغـة أخـرى؛ ويظهر هـذا في بعض

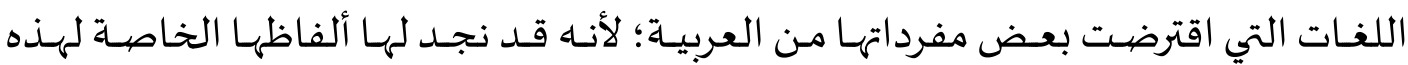
المفردات ولكن تفضّّل أن تطلق على تلك المفردات ألفاظلا عربيـة تفـاخرا بلغــة دينها؛ مثلا في إطلاق يوربـا لفظـ "جماعـة" Jamah الذذي هـو عربيّ الأصـل؛ مع أنّ لها لفظـا معيّنـا يعني هـذه المفـردة في لفتها الخاصـة وهـو "Ijoo" . وفي إطلاقهـا لفظ الرزق Orisiki على Ooro الـذي هـو 
لغتها الخاصة؛؛ وكذلك الأمر في إطلاق العربية بعض الألفاظ المقترضية على المفردات التي لها ما

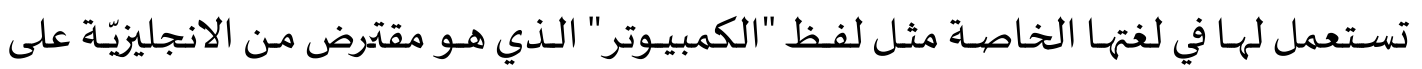
"الحاسوب" وإطلاق :الراديو" على المذياع؛ فليس القصيد من وراء إطلاق مثل الألفاظ المقترضية

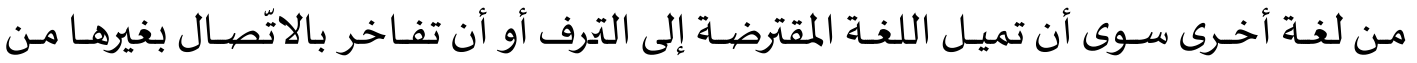
اللغات.

سرّ حاجة اللغة المقترضة إلى توفير مفهوم معاني المفردات؛ فهذا الدافع عامٌّ في جميع اللغات المقترضـة من غيرها؛ لأهها لا تعددم في لسـانها ما تطلق على مفرداتها ومسمّمياتها ولكنّها ترى من توسعة لغويّة أن تقترض ألفاظا أخرى تطلق على هذه المفردات في لغة أخرى مجاورة لها لتوفّر مفهوم معـاني المفردات؛ ونجـــ مثل هـذا في تـوفير يوربـا مفهوم معنى وقت معيّن عنــ غـروب الشمس أو بعده Irolee فتطلق عليه لفظا آخر مقترضيا من العربية وهو الآصال Asale، مثل توفيرها لمفهوم معنى Adajo فتطلق عليها لفظا عربيّا آخر وهو القاضي Alikali كما تطلق لفظ

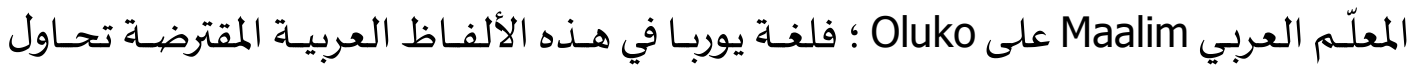

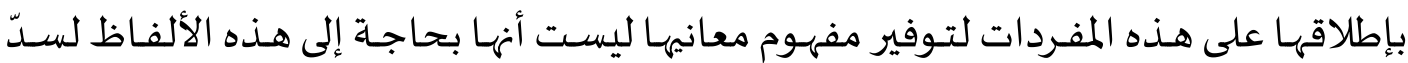
حاجة ما يعوزها من معاني هذه المفردات. سدّ حاجة اللغة المقترضة إلى مصطلحات معيّنة قد لم تألف بها لغة ما ولم يكن لها عهد بها من قبـل فأصيدق مثـال على هـذا، المصيطلحات الدينيّة التي أخــتها يوربـا مـن العربيـة؛ لأنها دخلت إليها عن طريق الإسلام؛ حيث كان أهل ما يطلق عليه اليوم نيجيريا لـم يدينوا بهذا الدين قبل مجيء العرب المسلمين إليهم لمهمّة تجاريّة -كما أسـلفنا-وعلى أيدي هؤلاء التجّار العرب شـرح الله صـدرهم للإسـام فـاعتنقوه دينـا وأخـذوا بعض مصططلحاتهم الدينيّة التي لا لا

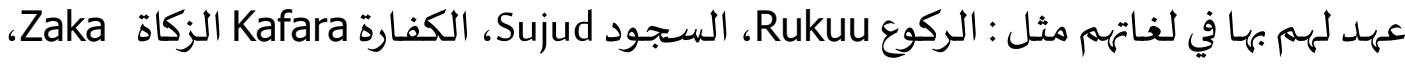

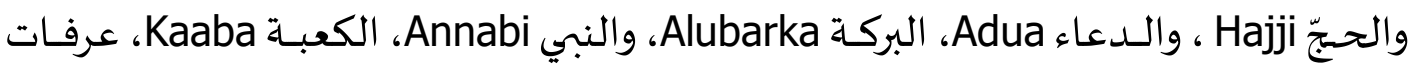

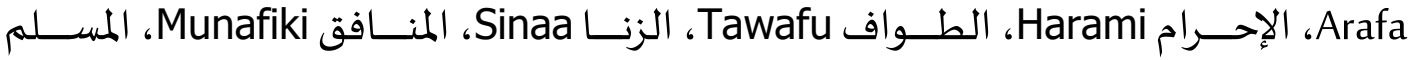
Musulumi، المؤمن Mumini، الكافر Keferi، كمـا أخذوا عنهم أسـماء الأيـام العربيّة وانتشر استعمالها حتى نسي الناس أسماءها المحليّة (Galandathi, 1982, p. 12) مثل : السبت

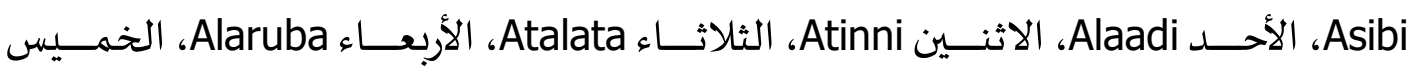


Alamisi قبل دخول الإسلام وهي تستعملها في لغتها على سبيل الاقتراض.

\section{طرق الاقتراض اللغوي}

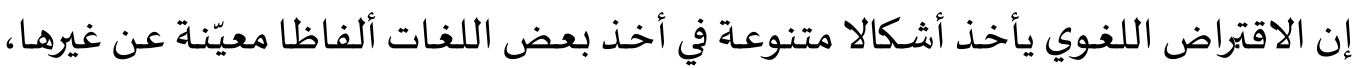
وقد تحتفظ اللغـة الآخذة عند النطق بألفاظ مقترضية حسب ما هي في اللغة المانحـة، وقد تسربّ إليها بعض التغيرات التي تجعل صورتها النطقية مخالفة لها؛ ومن هنا نجد أن هناط طرقا عدة تلجأ

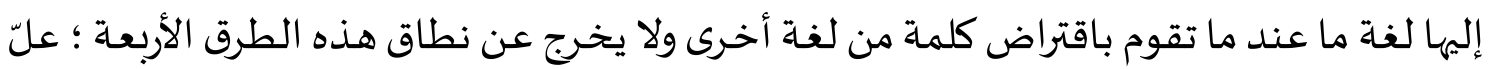
بعض هذه الطرق لا يوجد في اقتراض يوربا بعض ألفاظها من العربية وهي كما يلي:-

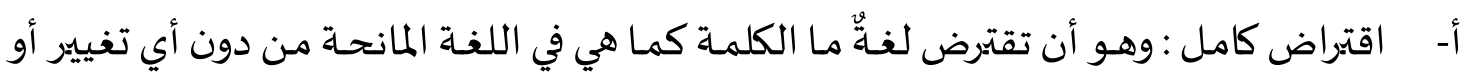
تعديل أو ترجمة نجد لذلك أمثالا عدّة من الألفاظ المقترضية في لغة يوربا من العربية منها كلمة Adua التي اقترضتها من كلمة "الدعاء" العربية، وكلمة Zakah من الزكاة، وكلمة Haji

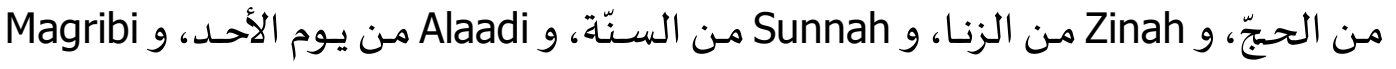

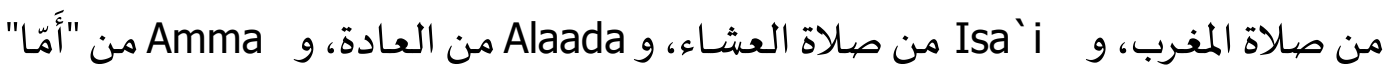

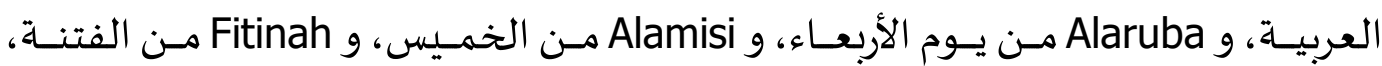
Musibahو من المصيبة،، و Arisiki من الرزق، و Annabi من النبي، و Alikali من القاضي، و و و و Sadaki والنطق بها في اللغة المقترضة فصورتها لدى المعطية مطابقة لصورتها لدى الآخذة فهي بذلك

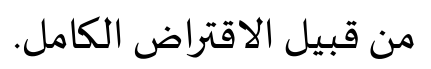
ب- اقتراض معدّل: فهـذا النـوع من الاقتبراض هو الذي يخضع لبعض تعديلات أو تغيييرات في اللغة المقترضة وتطلق عليها Arokoyo, 2012， p. 131) Indirect Borrowing ) ونجد لهذا القبيل من العربية بحيث كانت تقترض الكلمة وتعدل نطقها أو ميزانها الصرفي للتسهيل أو للاندماج (Al-Khouley, 1987, p. 98) مثلا كلمة "التلفاز " التي اقترضتها العربية من

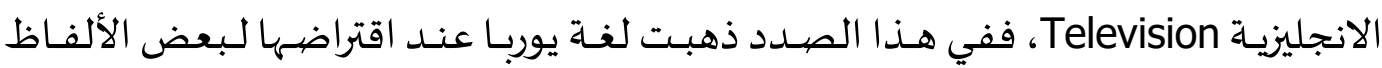
العربية اتجاهات معيّنة في تعديلها وتغيير ها فمنها :- 
ج- ما هي تغيير حركة الألفاظ؛ وذلك بأن تغيّر حركة كلمة عربية إلى حركة أخرى عند النطق بها

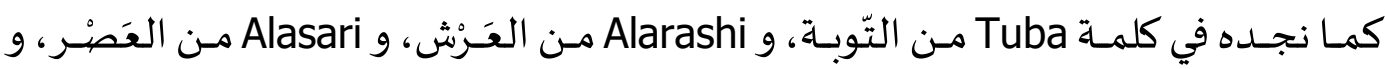

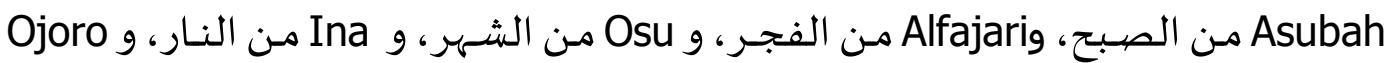
من الجور، و Saurah من الشورى، و Isoroo من العسر، و Inira من الضرّ، و Waasi من سن الوعظ وهكذا.

د- وما هي التغيير فيها بالقلب أو الإسقاط الحرفي وقد فصيّل الإلوريّ (El-lloriy, 2012, p. 137) الحـديث عـن هذا القبيل وبيّن مـا تحرفت لام تعريفهـ واوا بسـقوط حرف أو حـرفين وسـطا وطرفا وذلك في مثل : الله Olohun، والعيد Odun، والظهر Osan، والجبن Ojo، والماء Omi، والهبــة Ebun، والضــرّة Inira، واللــصّ Ole، والقلـب Okan، والهـوّة Iho، والتــالي Itele، والحمق Omugo، والقـوة Ogoo ـوما سـقطت لام تعريفهـ مـع سقوط حرف وسـطا أو آخرا ومن أمثاله Ina النار، و Alebu العيب، و Idin الديدان، و Furo الفروج، و Esin الخزي، و Tira الطرس، و Agan العقم، و Aro الأعرج، و Abere الإبرة، و Ala الأحلام، و Iro الهراء، و Alejo الجائي، و Tabi ارتاب، و Anfani من أنفعني، و Lodo لدى، و Eru الأسير ، و Suru الصـبر، و Patapata بتاتـا، و Isiro الحصـر، و Ajalu الأجـل، و Ewo أيّ، و L إلى، و و Owun هو، وهلم جرا ؛ وبالنظرة الفاحصة إلى تلك الألفاظ نجد أن فيها بعض التعديلات الناجمـة من قلب بعض حروفها وإسقاطها فجعل نشـر بتغييز طفيف في اللغـة المقترضية وتخالف النطق في اللغة المانحة.

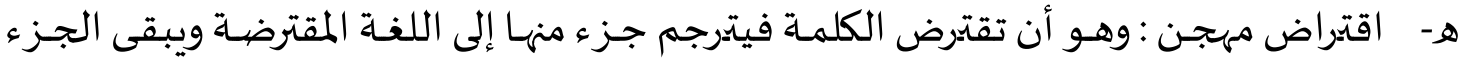
الآخر كما هو في لغة المصدر كما نجد ذلك في بعض مقترضات العربية مثل : صرنيم المأخوذة مـن Phoneme وصــرفيم المأخوذة مـن Morpheme حيـث تمـت ترجمـة الجـزء الأول مـن Al-Khouley, الكلمة من الانجليزية إلى العربية وبقي الجزء الثاني كما هو في الانجليزية (1987, p. 96 الواضحة في العربية حيث ترجمت الجزء الأول منـه إلى لفتها المحلية وهو "السـاحة" بمعنى

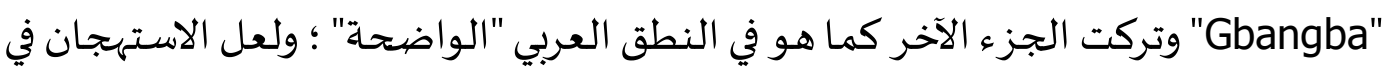


مثل هذا الاقتراض في التعامل مع بعض هذه الكلمات بترجمـة جزءء منها إلى اللغـة المقترضـة وترك الجزء الثاني مستصحبا حاله في لغة المصدر.

و- اقتراض مترجم ؛ وهو أن تقترض الكلمة عن طريق ترجمتها من لغة المصدر إلى اللغة المقترضية أي ترجمـة حرفيـة إلى كلمـة وطنيـة، ومثال ذلك الكلمـة الانجليزيـة Expression مأخوذة من الكلمة اللاتينية Expressio فهي لذلك كلمة مقترضة (Al-Khouley, 1987, p. 96) ومن أمثلة ذلك في يوربا كلمة Eeni بمعنى الحصير، و Eyin`ju سود العين أو بنت العين

\section{الألفاظ التي اقترضتها يوربا من اللغة العربية}

توجــد ألفـاظ عديـدة اقترضـتها يوربـا في لغتهـا مـن العربيـة وهي-بكثرتهـا- تنبي عـن أصـالتها العربية مع ما قد تطرّق إليها من التغيير والتعديل في بعضها -كما أسلفنا-ونأتي في الجدول ا الآتي بعض ما هي مقترضية في ألفاظ يوربا من العربية :

الجدول ا. الاقتراض اللغوي بين اللغة العربية ويوربا

\begin{tabular}{|c|c|c|c|}
\hline يوربا & العربية & يوربا & العربية \\
\hline Alubosa & البصل & Adua & الدعاء \\
\hline Omi & الماء & Isana & الزند \\
\hline Alasari & العصر & Alifajari & الفجر \\
\hline Magribi & المغرب & Asuba & الصبح \\
\hline Zakah & الزكاة & Isa' $i$ & العشاء \\
\hline Ituba & التوبة & Hajji & الحج \\
\hline Alaadi & الأحد & Jimoh & الجمعة \\
\hline Alafia & العافية & Alialikua & الحال قحّ \\
\hline Alaruba & الأربعاء & Atalata & الثلاثاء \\
\hline Asibi & السبت & Alamisi & الخميس \\
\hline Sanmo & السماء & Atinni & الاثنين \\
\hline Alamori & الأمر & Baale & البعل \\
\hline
\end{tabular}




\begin{tabular}{|c|c|c|c|}
\hline Musibah & المصيبة & Alaada & العادة \\
\hline Fitinah & الفتنة & Alikali & القاضي \\
\hline Ladani & المؤذن & Lemamu & الإمام \\
\hline Sawurah & الشورى & Wakati & الوقت \\
\hline Alarasi & العرش & Sadaki & الصيداق \\
\hline Arisiki & الرزق & Aanu & الحنون \\
\hline Sunnah & السنة & Șeriah & الشريعة \\
\hline Osa & الوثن & Musulumi & المسلم \\
\hline Asale & الأصيل & Ojoro & الجور \\
\hline Odun & العيد & Omugo & الحمق \\
\hline Odii & الحدّ & Oore & الخير \\
\hline Inira & الضرة & Ole & اللص \\
\hline Ebun & الهبة & Iho & الهوة \\
\hline Aleebu & العيب & Esaa & الخاصية \\
\hline Ero & الرخوة & Eroo & العير \\
\hline Faari & الفخر & Aaro & الأعرج \\
\hline
\end{tabular}

كانت لغة يوربا -شأن غيرها- من اللغات اقترضت بعض ألفاظها من العربية؛ وذلك نتيجة

الاحتكاك الحاصل من مجاوراتهما؛ حيث نزح التجّار العرب إلى نيجيريا لأهميّة التجارة وعرض سلعهم للبيع والتسويق؛ وعلى أيدي هؤلاء التجّار اعتنق أهل نيججيريا الاسلام وأخذوا عنهم لسـانهم العربي من خلال التعامل والتعليم منهم، وفي هذه الحالة أثّر بعض الألفاظ العربية في مفرداتهم اليوربويّة-مثل تأثيرها في غيرها من اللغات النيجيريّة المحليّة من هوسا وفلاته والنوبة- فأصبحت تلك الألفاظ مقترضية في يوربا، فمنها ما هي مطابقة لأصالتها العربية وما قد طرأ عليه التعديل بتغيير 


$$
\text { لكوض حروفها أو قلب مكانها أو الزيادة في بعضها؛ وهي-بمجموعها- تنبئ وتنمّ عن جذرها العربيّ }
$$

\section{قائمة المراجع}

Al-Khouley, M. A. (1987). El-Hayah Ma'a Lugatayn : Ats-Tsunaiyyah El-Lugawiyyah. Riyadh: Jamiah El-Malk Sahoud.

Arokoyo, B. E. (2012). Unlocking Morphology. Ilorin: Unilorin Press.

Ash-Shalqoney, A. (1980). Masodir El-Lugah. Riyadh: Imadah Shu un El-Maktabat bijamiat El-Malk Sahoud.

Assayoutey, J. d. A.-R. (_). El-Muz 'ir Fi Uloum El-Lugah Wa Adabiah. Cairo: El halabiy.

Ed-Deen, M. A. (2010). Muhadaratun fi Il 'm El-Lugah El-Ijtimaiyyah. Sawaribiyah: Dar El Hulum El-Lugawiyyah.

El-Afriqiyah, M. a. E. B. W .D. (2008). El-Lugah Wa thaqofah Fi Afriqiyah: Ibaratun an Aamal El-Mutamar Ed-Daoley Et-Thani Elladi Nadhomau Qism El Lugat Wa uqeema bi Mah 'ad El Buhuth Wad Dirasat El-Afriqiyah. Paper presented at the Jamiat El Qoirah, Cairo .

El-Fayrouzabadey, M. d. M .B. Y. (Ed.). Dar Et Thurath El Arabi.

El-Houryan, M. A. H. (2003). El-Urwat El-Athqoh bayna El- Qiraat wal Lahajaat._ :_ .

El-Iloriy, A. A. (2012). Asl Qobail Yoruba Wal Qobail El- Mujawirah fi Nigeria. Cairo: Maktabah Wahabah.

El-Kazourey, A. M. i. M .E.-H. (1988). Et-Tareeb fi Daoi IIm El-Lugah El-Muasir. Sudan: Dar Jamiat El-Khurtoum.

Esh-Shuwayrif, A. A. (1379 H). Et-Tadreebat El-Lugawiyyah. _ : Manshuratud Da`awah El-Islamiyyah.

Galandathi, S. A. S. (1982). Harakah El- Lugah El-Arabiyah Wa Adabiha fi Nigeria min Sanah 1804 Ilah 1966. Cairo: Dar El-Ma'arif.

Hoffer, B. L. (Producer). (2002). Language Borrowing and Language Diffusion. Retrieved from https://www.scribd.com/document/337525534/Hoffer-2002Language-Borrowing-and-language-diffusion-an-overview-pdf

Jinney, E.-K. I. (_). Thaqeeq Esh-Shaykh Muhammad Aliyy An-Najar. Cairo: Dar El Kutub El-Misriyyah.

Madkour, A. A. (1991). Funoun El-Lugah El -Arabiyyah. Cairo: Dar Ash-Shuwayrif Linnashr Wat Taodheehi.

Wikipedia (Producer). (2016). Yoruba People . 